\title{
Magnetic Properties of $\mathrm{L}_{0}$ Ordered FePt Films Prepared on a Fe-Si-B-Nb-Cu Soft Magnetic Underlayer
}

\author{
Ichiro Fujii ${ }^{1}$, Toshiyuki Shima ${ }^{2, *}$ and Koki Takanashi ${ }^{1}$ \\ ${ }^{1}$ Institute for Materials Research, Tohoku University, Sendai 980-8577, Japan \\ ${ }^{2}$ Department of Applied Physics and Informatics, Faculty of Engineering, Tohoku-Gakuin University, Tagajyo 985-8537, Japan
}

(001)-oriented FePt films with large perpendicular magnetic anisotropy have been obtained on a soft magnetic underlayer (SUL). A nanocrystalline $\mathrm{Fe}-\mathrm{Si}-\mathrm{B}-\mathrm{Nb}-\mathrm{Cu}$ alloy film has been chosen as SUL, showing the coercivity $H_{\mathrm{c}}$ of less than $80 \mathrm{~A} / \mathrm{m}$ after annealing at $400^{\circ} \mathrm{C}$. It has been found that the crystal orientation and magnetic properties of $\mathrm{FePt}$ films are improved by the introduction of a $\mathrm{MgO}$ interlayer between $\mathrm{FePt}$ and $\mathrm{Fe}-\mathrm{Si}-\mathrm{B}-\mathrm{Nb}-\mathrm{Cu}$. The strong (001) texture and the large coercivity of $565 \mathrm{kA} / \mathrm{m}$ have been obtained in the tri-layer structure of $\mathrm{Fe}-\mathrm{Si}-$ $\mathrm{B}-\mathrm{Nb}-\mathrm{Cu}(200 \mathrm{~nm}) / \mathrm{MgO}(5 \mathrm{~nm}) / \mathrm{FePt}(10 \mathrm{~nm})$.

(Received October 25, 2005; Accepted December 5, 2005; Published January 15, 2006)

Keywords: L1 $1_{0}$ ordered structure, soft magnetic underlayer, iron platinum thin film, sputtering

\section{Introduction}

Demand for high-density magnetic storage devices is unlimited and they have been expected to be downsized and to possess huge capacity. However, higher recording density requires smaller magnetic-particles, which faces a problem of thermal instability. $\mathrm{L}_{0}-\mathrm{FePt}$ ordered alloy has attracted much attention because of its high uniaxial magnetic anisotropy $K_{\mathrm{u}}\left(=7.0 \times 10^{6} \mathrm{~J} / \mathrm{m}^{3}\right)$ to solve the problem. ${ }^{1)} \mathrm{In}$ order to use the FePt alloy as the devices with a perpendicular magnetic recording system, a lot of work on the reduction of process temperature ${ }^{2-9)}$ and the control of the crystal orientation $^{10-12)}$ of FePt films has extensively been investigated. Recently, several studies on the combination of an FePt layer and a soft magnetic layer (SUL) have been made. ${ }^{13-16)}$ In this study, nanocrystalline $\mathrm{Fe}-\mathrm{Si}-\mathrm{B}-\mathrm{Nb}-\mathrm{Cu}$ alloy (Finemet, abbreviated as FMT hereafter ${ }^{17-19)}$ has been selected as a SUL, since it possesses a high thermal stability and low coercivity $H_{\mathrm{c}}$. A MgO interlayer has been introduced between FePt and FMT to obtain the (001) texture in the FePt layer. First, sputtering conditions for a FMT single layer film and a $\mathrm{MgO} / \mathrm{FePt}$ double layer film were separately optimized to achieve low $H_{\mathrm{c}}$ for FMT and high $H_{\mathrm{c}}$ for $\mathrm{FePt}$, respectively. Then, FMT $/ \mathrm{MgO} / \mathrm{FePt}$ tri-layer films were prepared, and the structure and magnetic properties have been investigated.

\section{Experimental Procedure}

Samples were prepared in an ultra-high-vacuum system (base pressure $\sim 1 \times 10^{-8} \mathrm{~Pa}$ ) using multiple dc sputtering onto glass substrates (Hoya corp., N5). FMT films were prepared at room temperature (R.T.) using a composite target, and then they were annealed at a temperature between 300 and $600^{\circ} \mathrm{C}$ for $1 \mathrm{~h}$ to improve soft magnetic properties. The composition of FMT films determined by electron probe X-ray microanalyzer (EPMA) to be $\mathrm{Fe}_{71.8} \mathrm{Si}_{14.2} \mathrm{~B}_{10.9}$ $\mathrm{Nb}_{1.9} \mathrm{Cu}_{1.2}$ (at\%). ${ }^{18,19)}$ High-purity $\mathrm{Ar}$ with gas pressure $P_{\mathrm{FMT}}(\mathrm{Ar})=0.13 \mathrm{~Pa}$ was flown during deposition, and the

*Corresponding author, E-mail: shima@imr.tohoku.ac.jp film thickness $t_{\text {FMT }}$ was varied in the range from 50 to $500 \mathrm{~nm}$. RF input power $E_{\mathrm{FMT}}$ was fixed at $100 \mathrm{~W}$. For $\mathrm{MgO} /$ FePt films, a $\mathrm{MgO}$ layer was deposited at R.T. using a sintered target followed by heating the substrate at $400^{\circ} \mathrm{C}$ for $1 \mathrm{~h}$. The Ar gas pressure $P_{\mathrm{MgO}}(\mathrm{Ar})$ was changed from 0.17 to 6.7 $\mathrm{Pa}$ and $\mathrm{RF}$ input power $E_{\mathrm{MgO}}$ was changed from 90 to 190 W. Subsequently, an FePt layer was deposited at the Ar gas pressure $P_{\mathrm{FePt}}(\mathrm{Ar})=0.67 \mathrm{~Pa}$ by co-sputtering of $\mathrm{Fe}$ and Pt targets. RF input power $E_{\mathrm{Fe}}$ was changed from 7 to $15 \mathrm{~W}$, while $E_{\mathrm{Pt}}$ was fixed at $5 \mathrm{~W}$. The composition of FePt was changed in the range from $\mathrm{Fe}_{35} \mathrm{Pt}_{65}$ to $\mathrm{Fe}_{60} \mathrm{Pt}_{40}$ (at\%), which were determined by EPMA. The film thicknesses were fixed at $t_{\mathrm{MgO}}=t_{\mathrm{FePt}}=10 \mathrm{~nm}$. For tri-layer films, the combination of optimized sputtering conditions for FMT and $\mathrm{MgO} / \mathrm{FePt}$ films were used. Structural characterizations were performed by $\mathrm{X}$-ray diffractometry (XRD) with $\mathrm{Cu}-\mathrm{K} \alpha$ radiation and transmission electron microscopy (TEM). Magnetic properties were measured by a superconducting quantum interference device (SQUID) magnetometer, a vibrating sample magnetometer (VSM), and polar magneto-optical Kerr effect (MOKE) at room temperature.

\section{Results and Discussion}

\subsection{Optimization for FMT films}

XRD patterns for FMT films in the as deposited state and in the annealed states with different temperatures $T_{\mathrm{a}}$ are shown in Fig. 1.

The broad patterns corresponding with an amorphous phase of the glass substrate at around $25^{\circ}$ and a nanocrystalline of bcc Fe phase at both $45^{\circ}$ and $65^{\circ}$ are observed in the as deposited film. After annealing at $450^{\circ} \mathrm{C}$, the peak corresponding with bcc Fe 110 appears. It has been found from high resolution TEM observation that $\mathrm{Fe}$-based fine particles with the lateral size of about several $\mathrm{nm}$ are formed even for $T_{\mathrm{a}}=400^{\circ} \mathrm{C}$. It is noted that this observed crystallization temperature is slightly lower than that of the liquid quenched $\mathrm{Fe}_{73.5} \mathrm{Si}_{13.5} \mathrm{~B}_{9} \mathrm{Nb}_{3} \mathrm{Cu}_{1}$ (at\%) ribbon samples reported previously. ${ }^{17)}$ This is thought to arise from the difference in composition.

The effect of post-annealing on the coercivity $H_{\mathrm{c}}$ for FMT 


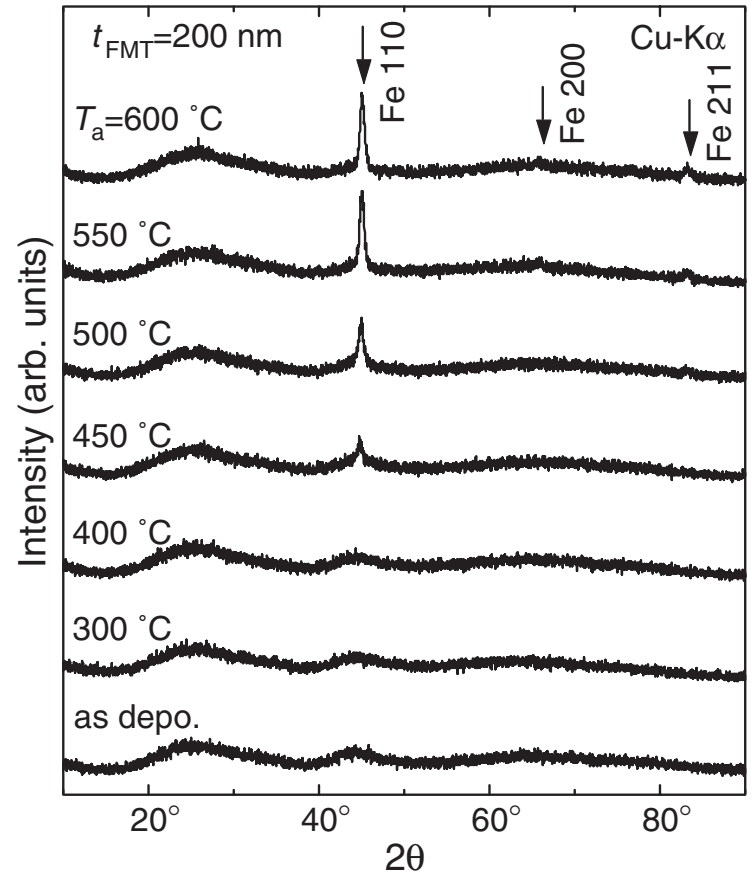

Fig. 1 XRD patterns for $\mathrm{Fe}_{71.8} \mathrm{Si}_{14.2} \mathrm{~B}_{10.9} \mathrm{Nb}_{1.9} \mathrm{Cu}_{1.2}$ thin films with different annealing temperatures; $T_{\mathrm{a}}=300,400,450,500,550$ and $600^{\circ} \mathrm{C}$. The Ar pressure during deposition $P_{\mathrm{FMT}}(\mathrm{Ar})$ and $\mathrm{RF}$ input power $E_{\mathrm{FMT}}$ were $0.13 \mathrm{~Pa}$ and $100 \mathrm{~W}$, respectively.

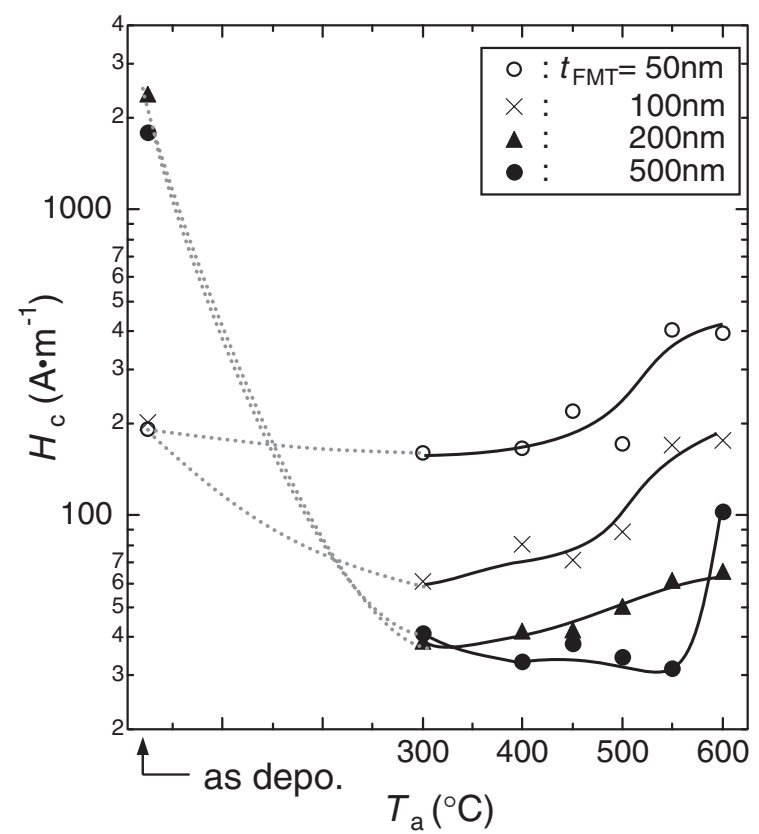

Fig. 2 Annealing temperature $T_{\mathrm{a}}$ dependence of coercivity $H_{\mathrm{c}}$ for $\mathrm{Fe}_{71.8^{-}}$ $\mathrm{Si}_{14.2} \mathrm{~B}_{10.9} \mathrm{Nb}_{1.9}-\mathrm{Cu}_{1.2}$ thin films. The film thicknesses $t_{\mathrm{FMT}}$ were 50, 100, 200 , and $500 \mathrm{~nm}$.

films with different film thicknesses $t_{\mathrm{FMT}}$ is shown in Fig. 2 . For both $t_{\mathrm{FMT}}=200$ and $500 \mathrm{~nm}, H_{\mathrm{c}}$ decreases drastically at $T_{\mathrm{a}}=300^{\circ} \mathrm{C}$, possibly due to the relaxation of internal stress induced during deposition. These films annealed at $T_{\mathrm{a}}=300-550^{\circ} \mathrm{C}$ also exhibit low $H_{\mathrm{c}}$ less than $80 \mathrm{~A} / \mathrm{m}$ $(\approx 1 \mathrm{Oe})$, indicating that the films possess high thermal stability. However, further annealing at the temperature

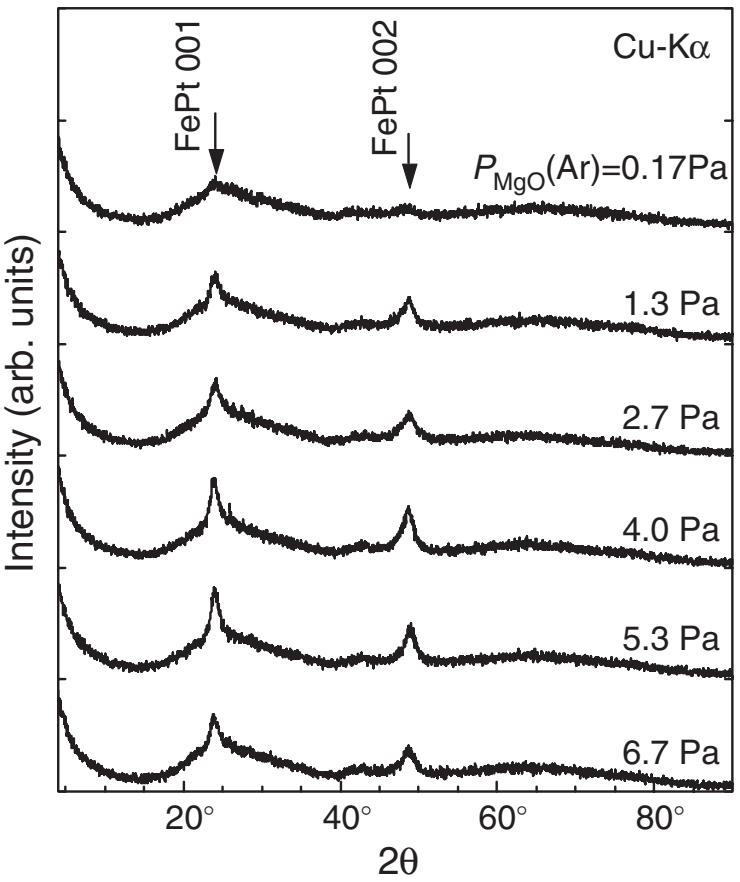

Fig. 3 XRD patterns for FePt thin films with different Ar pressures during the deposition of $\mathrm{MgO}$ layers; $P_{\mathrm{MgO}}(\mathrm{Ar})=0.17,1.3,2.7,4.0,5.3$, and 6.7 $\mathrm{Pa}$. The RF input power $E_{\mathrm{MgO}}$ and the film composition were fixed at $150 \mathrm{~W}$ and $\mathrm{Fe}_{43} \mathrm{Pt}_{57}$, respectively.

more than $550^{\circ} \mathrm{C}$ result in a sudden increase of $H_{\mathrm{c}}$ for $t_{\mathrm{FMT}}=500 \mathrm{~nm}$.

\subsection{Optimization of $\mathrm{MgO} / \mathrm{FePt}$ films}

XRD patterns for $\mathrm{MgO} / \mathrm{FePt}$ films with different $P_{\mathrm{MgO}}(\mathrm{Ar})$ are shown in Fig. 3. The RF input power and the film composition were fixed at $E_{\mathrm{MgO}}=150 \mathrm{~W}$ and $\mathrm{Fe}_{43} \mathrm{Pt}_{57}$, respectively. No intense peak is not observed for $P_{\mathrm{MgO}}(\mathrm{Ar})=$ $0.17 \mathrm{~Pa}$. However, for $P_{\mathrm{MgO}}(\mathrm{Ar})$ more than $1.3 \mathrm{~Pa}$, the fundamental 002 and superlattice 001 peaks of the $\mathrm{L} 1_{0}$ phase are clearly observed, indicating the formation of $\mathrm{L}_{0}$ ordered structure in the FePt layer. The most intense peak is observed for $P_{\mathrm{MgO}}(\mathrm{Ar})=5.3 \mathrm{~Pa}$.

Figure 4 also shows XRD patterns for $\mathrm{MgO} / \mathrm{FePt}$ films with different $E_{\mathrm{MgO}} . P_{\mathrm{MgO}}(\mathrm{Ar})$ and the film composition were fixed at 5.3 $\mathrm{Pa}$ and $\mathrm{Fe}_{43} \mathrm{Pt}_{57}$, respectively. For $E_{\mathrm{MgO}}$ more than $110 \mathrm{~W}$, the fundamental 002 and superlattice 001 peaks of the $\mathrm{L1}_{0}$ phase are clearly observed, indicating the formation of $\mathrm{L}_{0}$ ordered structure in the FePt layer. For $E_{\mathrm{MgO}}$ between 130 and $190 \mathrm{~W}$, no remarkable change is observed.

Magnetization curves for $\mathrm{MgO} / \mathrm{FePt}$ films with different $E_{\mathrm{MgO}}$ are shown in Fig. 5. The magnetic field was applied in the direction perpendicular to the film $\left(H_{\perp}\right.$ : solid line) and in the in-plane direction $\left(H_{/ /}\right.$: dotted line). For $E_{\mathrm{MgO}}=90 \mathrm{~W}$, only small coercivity in the perpendicular direction $H_{\mathrm{c} \perp}$ of $250 \mathrm{kA} / \mathrm{m}$ is obtained. With increasing $E_{\mathrm{MgO}}$, a large value of $H_{\mathrm{c} \perp}$ of $550 \mathrm{kA} / \mathrm{m}$ is achieved for $E_{\mathrm{MgO}}$ between $110 \mathrm{~W}$ and $150 \mathrm{~W}$. The further increase of $E_{\mathrm{MgO}}$ results in the decrease of $H_{\mathrm{c} \perp}$.

The Fe concentration $x$ (at $\%$ ) dependence of $K_{\mathrm{u}}$ for $\mathrm{MgO} /$ $\mathrm{Fe}_{x} \mathrm{Pt}_{100-x}$ thin films is shown in Fig. 6. $P_{\mathrm{MgO}}(\mathrm{Ar})$ and $E_{\mathrm{MgO}}$ were fixed at $5.3 \mathrm{~Pa}$ and $150 \mathrm{~W}$, respectively. The results for 


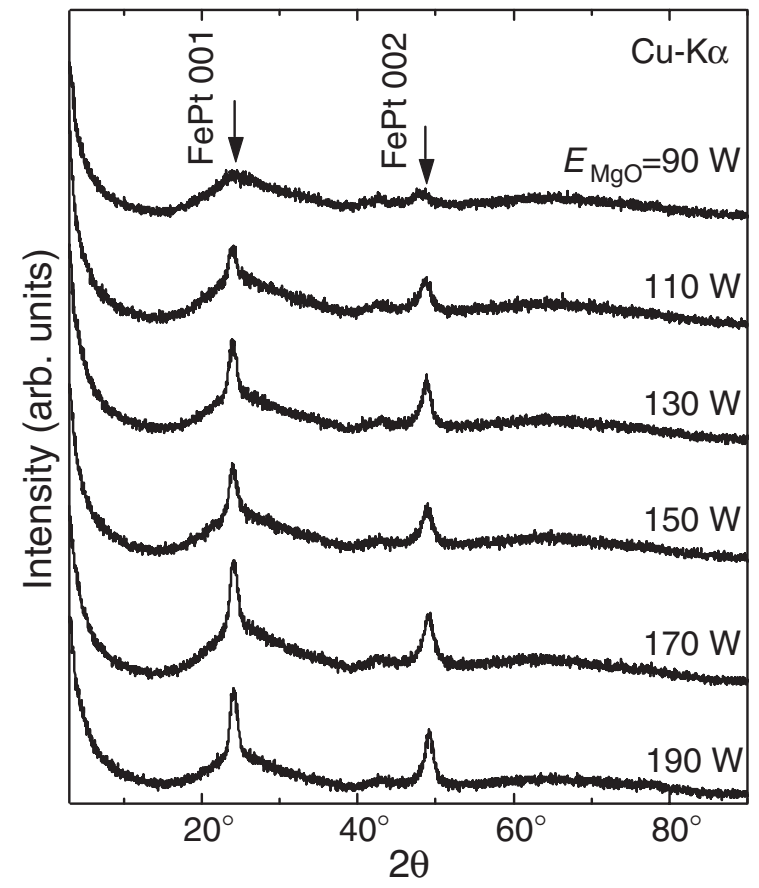

Fig. 4 XRD patterns for FePt thin films with different RF input powers; $E_{\mathrm{MgO}}=90,110,130,150,170$ and $190 \mathrm{~W} . P_{\mathrm{MgO}}(\mathrm{Ar})$ and the film composition were fixed at $5.3 \mathrm{~Pa}$ and $\mathrm{Fe}_{43} \mathrm{Pt}_{57}$, respectively.

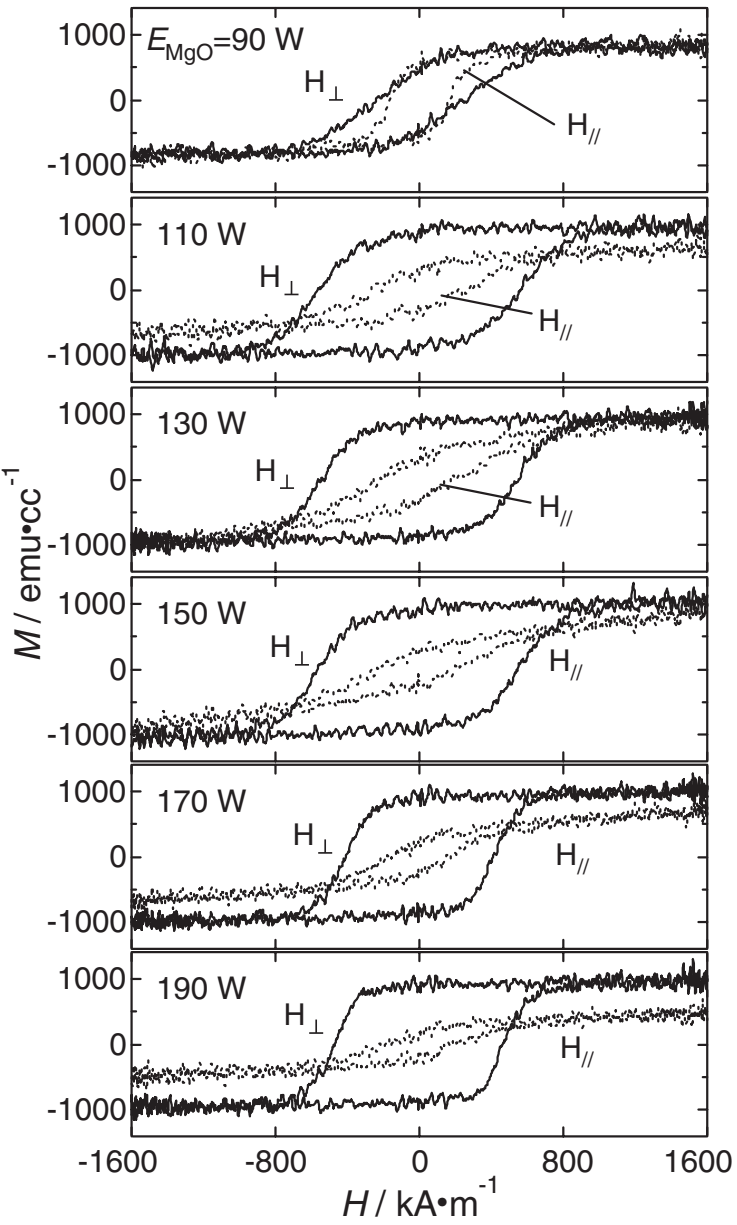

Fig. 5 Magnetization curves for $\mathrm{MgO} / \mathrm{FePt}$ films with different $\mathrm{RF}$ input powers of $\mathrm{MgO}, E_{\mathrm{MgO}}=90,110,130,150,170$ and $190 \mathrm{~W} \cdot P_{\mathrm{MgO}}(\mathrm{Ar})$ and the film composition were fixed at $5.3 \mathrm{~Pa}$ and $\mathrm{Fe}_{43} \mathrm{Pt}_{57}$, respectively.

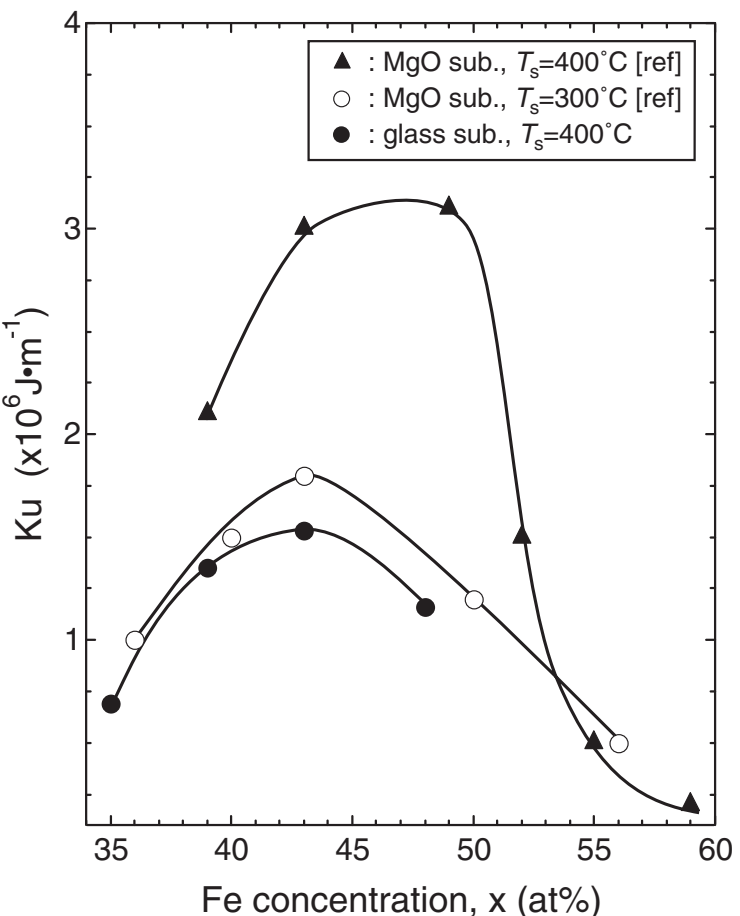

Fig. $6 \mathrm{Fe}$ concentration $x($ at $\%)$ dependence of $K_{\mathrm{u}}$ for $\mathrm{Fe}_{x} \mathrm{Pt}_{100-x}$ thin films prepared with different deposition conditions. $\boldsymbol{\Delta}, \bigcirc$, and $\bullet$ denote the results for FePt films prepared at the substrate temperature $T_{\mathrm{s}}=400^{\circ} \mathrm{C}$ on a $\mathrm{MgO}(001)$ substrate [Ref. 21], FePt films prepared at $T_{\mathrm{s}}=300^{\circ} \mathrm{C}$ on a $\mathrm{MgO}(001)$ substrate [Ref. 20] and FePt films prepared at $T_{\mathrm{s}}=400^{\circ} \mathrm{C}$ on a glass substrate (this work), respectively.

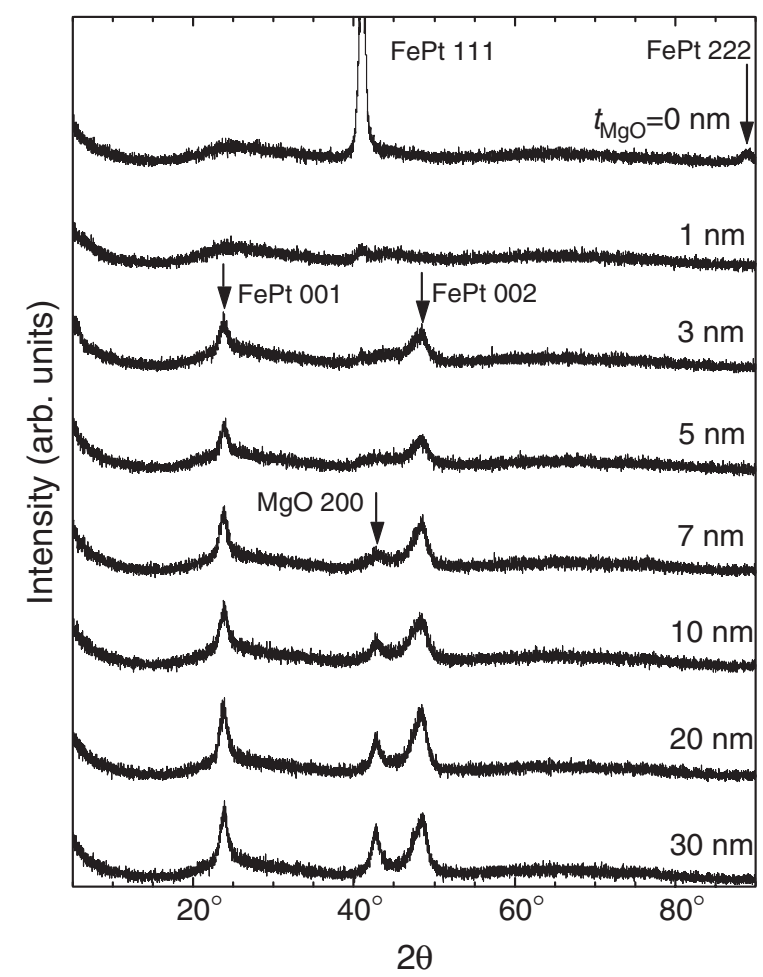

Fig. 7 XRD patterns for FMT $(200 \mathrm{~nm}) / \mathrm{MgO}\left(t_{\mathrm{MgO}} \mathrm{nm}\right) / \mathrm{FePt}(10 \mathrm{~nm})$ trilayer films with different $\mathrm{MgO}$ thicknesses: $t_{\mathrm{MgO}}=0,1,3,5,7,10,20$, and $30 \mathrm{~nm}$. 


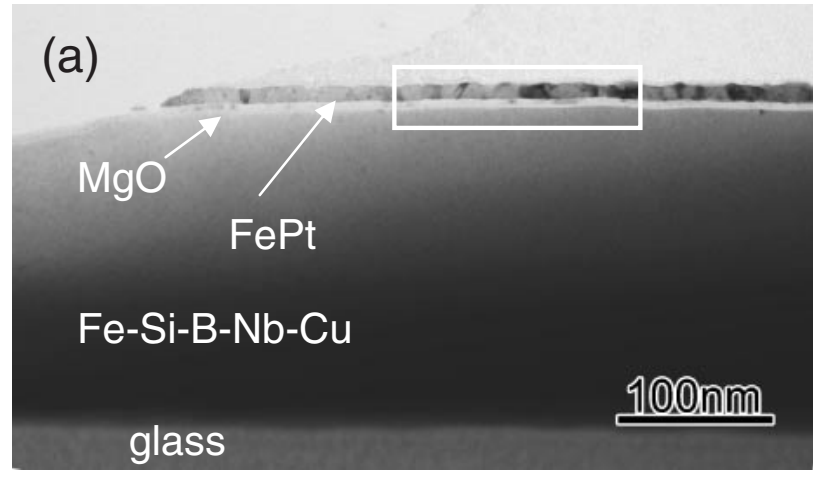

(b)
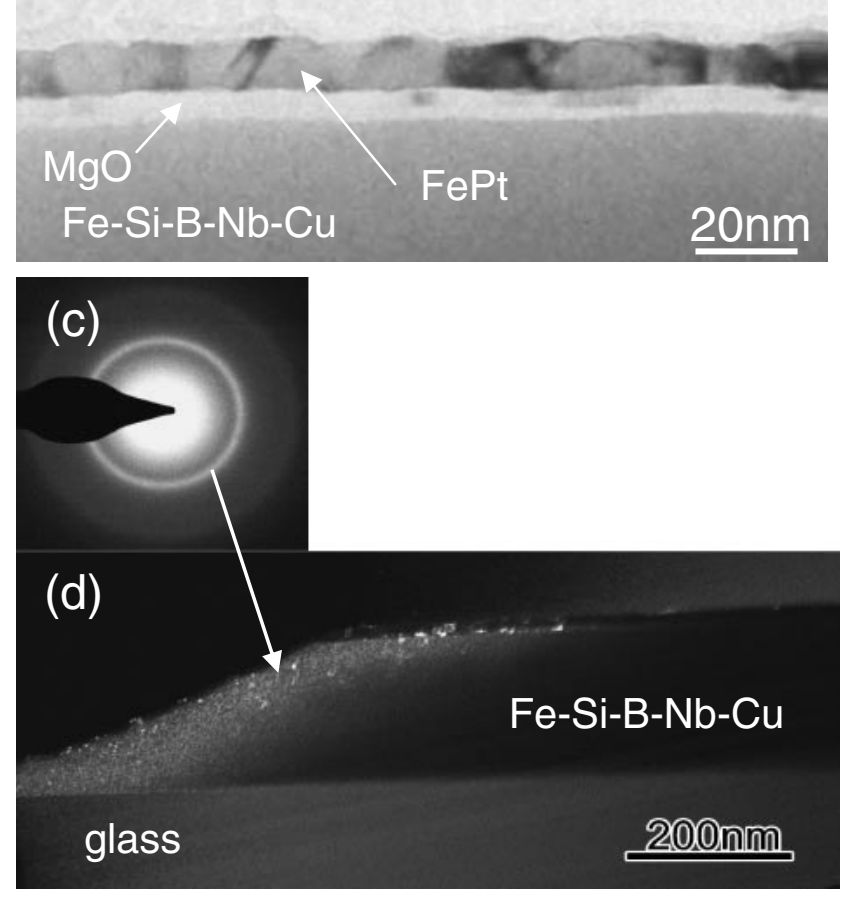

Fig. 8 Cross sectional TEM images for a FMT $(200 \mathrm{~nm}) / \mathrm{MgO}(5 \mathrm{~nm}) /$ FePt $(10 \mathrm{~nm})$ thin film. The enlarged image of the part marked in (a) is shown in (b). The selected area diffraction (SAD) pattern in the FMT region and the dark field image taken with the diffraction ring for bcc $\mathrm{Fe}$ are shown in (c) and (d), respectively.

FePt films prepared on $\mathrm{MgO}$ (001) single crystal substrates at different substrate temperatures $T_{\mathrm{s}}$ are also shown for references. ${ }^{20,21)}$ For the films prepared on $\mathrm{MgO}$ single crystal substrates, the optimum Fe concentration for exhibiting high $K_{\mathrm{u}}$ is shifted to a Pt-rich region from the equiatomic composition. This tendency is consistent with the present result on the films prepared on a glass substrate. The highest $K_{\mathrm{u}}$ of $1.5 \times 10^{6} \mathrm{~J} / \mathrm{m}^{3}$ is obtained for $x=43$.

\subsection{Structure and magnetic properties of FMT/MgO/ FePt tri-layer films}

For the preparation of $\mathrm{FMT} / \mathrm{MgO} / \mathrm{FePt}$ trilayer films, FMT and MgO layers were first deposited at R.T., and then they were annealed in the UHV condition at $400^{\circ} \mathrm{C}$ for 1 hour. $P_{\mathrm{MgO}}(\mathrm{Ar})$ and $E_{\mathrm{MgO}}$ were set at $5.3 \mathrm{~Pa}$ and $150 \mathrm{~W}$, respectively. Subsequently, an FePt layer was deposited at $400^{\circ} \mathrm{C}$. The composition of $\mathrm{FePt}$ was fixed at $\mathrm{Fe}_{43} \mathrm{Pt}_{57}$. XRD patterns

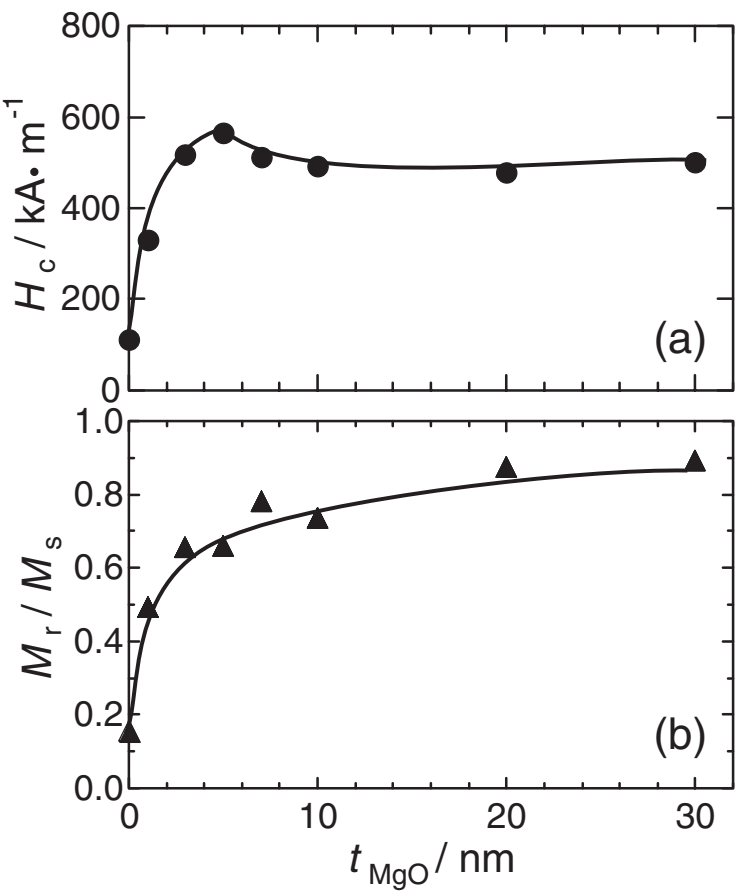

Fig. $9 t_{\mathrm{MgO}}$ dependence of $H_{\mathrm{c}}$ and $M_{\mathrm{r}} / M_{\mathrm{s}}$ for FMT $(200 \mathrm{~nm}) / \mathrm{MgO}\left(t_{\mathrm{MgO}}\right.$ $\mathrm{nm}) / \mathrm{FePt}(10 \mathrm{~nm})$ tri-layer films.

for structure of FMT $(200 \mathrm{~nm}) / \mathrm{MgO}\left(t_{\mathrm{MgO}} \mathrm{nm}\right) / \mathrm{FePt}(10 \mathrm{~nm})$ tri-layer films with different $\mathrm{MgO}$ thicknesses $t_{\mathrm{MgO}}$ are shown in Fig. 7. The peaks of FePt 111 and FePt 222 are clearly observed for $t_{\mathrm{MgO}}=0$, indicating the formation of a (111) texture. However, for $t_{\mathrm{MgO}}=1 \mathrm{~nm}$, the intensities of FePt 111 and 222 peaks drastically decrease, and they disappear for $t_{\mathrm{MgO}} \geq 3 \mathrm{~nm}$. Instead, the fundamental 002 and superlattice 001 peaks of the $\mathrm{L} 1_{0}$ phase are clearly observed for $t_{\mathrm{MgO}} \geq 3 \mathrm{~nm}$, indicating that the films possess a (001) texture in the FePt layer. With further increasing $t_{\mathrm{MgO}}$, the intense peak of $\mathrm{MgO} 200$ starts to appear.

Figures 8 shows cross sectional TEM images for a FMT $(200 \mathrm{~nm}) / \mathrm{MgO}(5 \mathrm{~nm}) / \mathrm{FePt}(10 \mathrm{~nm})$ film. The flat interfaces between FMT and $\mathrm{MgO}$ layers and between $\mathrm{MgO}$ and FePt layers are observed. The selected area diffraction pattern in the SUL region [Fig. 8(c)] shows that it mainly consists of amorphous structure, however nano-meter scale fine particles are observed in the dark field image [Fig. 8(d)], which was taken with the diffraction ring of bcc Fe, indicating that nanocrystallines are precipitated.

$H_{\mathrm{c} \perp}$ and the squareness ratio $M_{\mathrm{r}} / M_{\mathrm{s}}$ for FMT $(200 \mathrm{~nm}) /$ $\mathrm{MgO}\left(t_{\mathrm{MgO}} \mathrm{nm}\right) / \mathrm{FePt}(10 \mathrm{~nm})$ tri-layer films as a function of $t_{\mathrm{MgO}}$ are shown in Fig. 9. $H_{\mathrm{c} \perp}$ increases with increasing $t_{\mathrm{MgO}}$ and almost saturates for $t_{\mathrm{MgO}} \geq 5 \mathrm{~nm}$. The maximum $H_{\mathrm{c} \perp}$ of $565 \mathrm{kA} / \mathrm{m}$ is achieved for $t_{\mathrm{MgO}}=5 \mathrm{~nm}$.

\section{Summary}

FMT/MgO/FePt thin films with a strong (001) texture in the FePt layer were prepared on glass substrates. It has been found that the (001) texture of FePt films is obtained by the introduction of a $\mathrm{MgO}$ interlayer and the large $H_{\mathrm{c}}$ of $565 \mathrm{kA} /$ $\mathrm{m}$ is obtained for a FMT $(200 \mathrm{~nm}) / \mathrm{MgO}(5 \mathrm{~nm}) / \mathrm{FePt}(10 \mathrm{~nm})$ tri-layer film. This study suggests that FMT will be one of the 
candidates for SUL to realize FePt perpendicular magnetic recording media with high thermal stability.

\section{Acknowledgement}

The authors would like to acknowledge HOYA corp. for providing glass substrates and Dr. Y. K. Takahashi, National Institute for Materials Science for TEM observation.

\section{REFERENCES}

1) D. Weller and A. Moser: IEEE Trans. Magn. 35 (1999) 4423.

2) T. Maeda, T. Kai, A. Kikitsu, T. Nagase and J. Akiyama: J. Appl. Phys. 80 (2002) 2147.

3) Y. K. Takahashi, M. Ohnuma and K. Hono: J. Magn. Magn. Mater. 246 (2002) 259.

4) D. Revelosona, C. Cappert, V. Mathet and H. Bernas: J. Appl. Phys. 87 (2000) 5771.

5) C. P. Luo and D. J. Sellmyer: IEEE Trans. Magn. 31 (1995) 2764.

6) Y. Endo, N. Kikuchi, O. Kitakami and Y. Shimada: J. Appl. Phys. 89 (2001) 7065 .

7) T. Shima, T. Moriguchi, S. Mitani and K. Takanashi: Appl. Phys. Lett.
80 (2002) 288.

8) T. Suzuki, K. Harada, N. Honda and K. Ouchi: J. Magn. Magn. Mater. 193 (1999) 85

9) Y. K. Takahashi, M. Ohnuma and K. Hono: Jpn. J. Appl. Phys. 40 (2001) L1367.

10) H. Sakagami, T. Miyazaki, O. Kitakami and Y. Shimada: J. Magn. Soc. Jpn. 25 (2001) 847.

11) Y. Xu, J. S. Chen and J. P. Wang: Appl. Phys. Lett. 80 (2002) 3325.

12) T. Sakurai, O. Kitakami and Y. Shimada: Digest on the 26th annual conference on Magnetics in Japan (2002) 305.

13) T. Suzuki: Digests of PMRC 2004 (2004) 02pC-03.

14) T. Suzuki, Z. Zhang, A. K. Singh, J. Yin, A. Perumal and H. Osawa: IEEE Trans. Magn. 41 (2005) 555.

15) S. Kumar, A. G. Roy and D. E. Laughlin: IEEE Trans. Magn. 40 (2004) 2380.

16) M. L. Yan, X. Z. Li, L. Gao, S. H. Liou, D. J. Sellmyer, R. J. M. van de Veerdonk and K. W. Wierman: Appl. Phys. Lett. 83 (2003) 3332.

17) Y. Yoshizawa, S. Oguma and K. Yamauchi: J. Appl. Phys. 64 (1988) 6044.

18) N. Kataoka, T. Shima and H. Fujimori: J. Appl. Phys. 70 (1991) 6238.

19) T. Shima, N. Kobayashi, N. Kataoka and H. Fujimori: Sci. Rep. Res. Inst. Tohoku Univ. Ser. A 36 (1992) 224.

20) T. Seki, T. Shima, K. Takanashi, Y. Takahashi, E. Matsubara and K. Hono: Appl. Phys. Lett. 82 (2003) 2641.

21) M. Nakamura: Master thesis of Tohoku University (2003). 